\title{
A group of assassin fly pupae preserved in a single piece of Eocene amber
}

\author{
JoACHIM T. HAUG, Christina Nagler, Carolin HaUg \& MARIE K. HÖRNIG
}

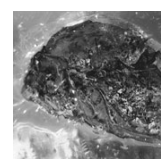

\begin{abstract}
Holometabolous insects represent a mega-diverse group of organisms that are dominant in most terrestrial faunas. All holometabolous insects develop via a specific transitory stage between the last larval stage and the adult, called the pupa. While insects in general have a comparably good fossil record, fossils of pupae of holometabolous insects are relatively rare. We report here four pupal specimens preserved in a single piece of amber. These represent pupa stages of assassin flies, Asilidae, and are most likely representatives of Laphriinae. While dipterans are quite common in the fossil record, especially in amber, representatives of Asilidae are comparably rare. Combining the rarity of the systematic group and the rarity of the specific life stage, these fossil remains of assassin fly pupae are extremely unusual; to date only a single specimen has been depicted in the literature. We discuss the importance of our new finding and possible interpretations regarding behavioural aspects of the group enclosed in amber. - Key words: fossil pupa, Asilidae, Laphriinae, amber, fossilised behaviour.
\end{abstract}

HAUG, J.K., NAGLER, C., HAUG, C. \& HöRNIG, M.K. 2017. A group of assassin fly pupae preserved in a single piece of Eocene amber. Bulletin of Geosciences 92(3), 283-295 (5 figures), Czech Geological Survey, Prague, ISSN 1214-1119. Manuscript received July 14, 2016; accepted in revised form July 5, 2017; published online August 3, 2017; issued September 30, 2017.

Joachim T. Haug \& Carolin Haug, Ludwig-Maximilians-Universität München, Biocenter, Department Biology II, Großhaderner Straße 2, 82152 Planegg-Martinsried \& GeoBio-Center of the LMU Munich, Richard-Wagner-Str 10, 80333 München, Germany; joachim.haug@palaeo-evo-devo.info, carolin.haug@palaeo-evo-devo.info • Christina Nagler, Ludwig-Maximilians-Universität München, Biocenter, Department Biology II, Großhaderner Straße 2, 82152 Planegg-Martinsried, Germany; christina.nagler@campus.Imu.de• Marie K. Hörnig, Ernst-Moritz-Arndt-Universität Greifswald, Zoologisches Institut, Cytologie und Evolutionsbiologie, Soldmannstraße 23, 17487 Greifswald, Germany; marie.hoernig@palaeo-evo-devo.info

Flying insects (Pterygota) represent a dominate life form on Earth. Within insects, the most diverse lineages are all ingroups of Holometabola, hence this group has been often named as the most successful ingroup of insects (however, this claim has also been applied to beetles, an ingroup of Holometabola). Holometabolous insects gained their name from a specific post-embryonic developmental pattern, which includes a so-called pupa.

\section{The insect pupa}

The pupa is usually understood as a kind of "intermediate", mediating the transition from the larva to the adult (imago). The pupa is therefore often treated as something quite special. Yet, in other arthropod groups transitionary stages are known also, e.g. the megalopa in many lobster-like decapod crustaceans fulfils a comparable function (e.g. Rudolf et al. 2016 and references therein). In a wider view, the pupa can be seen as a highly specialised larval stage.
Immature stages of insects and also arthropods as a whole (including "classical" larvae, pupae, but also nymphs) tend to be considered less often scientifically than adults (e.g. Minelli et al. 2006). This applies to both extant and fossil forms. Fossil immature stages are more difficult to interpret in many cases, but have the potential to reveal important features that adult forms could not, and illuminate aspects of the life history, niche differentiation between adult and larva or the evolution of specialised larval forms (see more extended discussion in, e.g., Haug et al. 2013a, 2015a, 2016).

\section{Fossil pupae}

Insect pupae may also be quite rare in the fossil record, as well as being rarely described. Pupae that are aquatic have a higher potential to be preserved in sedimentary deposits than those from terrestrial forms, and several examples are known, for example, from limestones (e.g. Hugueney et al. 
1990, Johnston \& Borken 1998, Davis et al. 2010, Lukashevich 2012, Lukashevich \& Przhiboro 2015, see also references in Andersen et al. 2015).

Amber has great potential for preserving insects, but most commonly it is adults that are found. Larvae appear to be rare (though nymphs, in some groups, are quite widespread), and pupae seem even less abundant. Weitschat \& Wichard (1998) in their large overview work only report pupae of lacewings (Planipennia), ants (Formicidae) and dipterans (Tipulinae; Anisopodidae). Pupae of ants in amber have also been reported by Brandão et al. (1998) and Perkovsky (2008). Ant pupae have a certain indirect mobility, due to the fact that they are carried around by their conspecific workers. Comparably, pupae of strepsipterans (Poinar 2004) have been found, and they are indirectly mobile due to their host.

The rarity even in amber (Andersen et al. 2015, Fischer 2015) is quite likely caused by the (largely) non-mobile pupae (but see above), and hence likely represents a true rarity, there might also be a certain "taxonomic bias". The identification of pupae to a species is often challenging (e.g. Veltz et al. 2007), also in many extant groups pupae are often not described, making comparisons difficult. Nevertheless, fossil pupae have some potential to contribute scientifically (Lukashevich \& Przhiboro 2015; see also above).

\section{Lifestyle of Asilidae}

Asilidae (assassin flies) is a group of dipteran, holometabolous insects with currently more than 7,000 described species (Pape et al. 2011, Wolff \& Lamas 2016) with a worldwide distribution (Hull 1962). Despite niche differentiation (Lavigne et al. 1978) concerning habitat (Dennis et al. 2008), and a specific flight period in the year (Cannings 1997), all asilids have certain common features concerning their lifestyle. Adult and immature asilid males and females feed on other arthropods, mainly insects (Musso 1978).

The adults prey on spiders, beetles, butterflies, bees, wasps and other insects. They inject saliva containing neurotoxic and proteolytic enzymes into their prey (Wood 1981, Hayat 1997), which rapidly immobilises it and dissolves the tissue, allowing the assassin fly to feed on the liquid (Musso 1978). Larval forms are predatory or parasitic, mainly on beetle larvae (depending on the criteria for parasitism; more details in the discussion). The lifestyle of asilids has been interpreted to provide a healthy balance between insect populations in different habitats (Shurovnekov 1962, Joern \& Rudd 1982).

Females lay their eggs in groups on leaves or stems of low-growing plants and grasses, in crevices, within soil (digging a hole with their ovipositor), under bark, or in burrows of wood-boring insects into dead wood (Cannings 1989). Some species, e.g. Stichopogom trifasciatus, Machimus callidus, Efferia frewingi, have been reported to show a searching behaviour for a suitable place to deposit their eggs by investigating the possible oviposition sites with their ovipositors (Pritchard 1935; Lavigne \& Dennis 1975, 1980; Dennis \& Lavigne 1979; Dennis et al. 1986; Castelo \& Corley 2004; Dennis 2012, 2013).

One factor for determination of the right oviposition site is the aggregation of possible hosts/prey larvae in the field (Castelo \& Capurro 2000). The larvae are able to actively locate their hosts using chemical information provided by the hosts (Castelo \& Lazzari 2004). The first instar larva of asilids, the so-called planidium (Musso 1981) can move and actively search for their hosts (Crespo \& Castelo 2009). Similar location behaviour has also been reported for other dipteran larvae that are parasitic on different beetles (Godfray 1994, Brodeur \& Boivin 2004).

Asilids have been found in the fossil record, but rarely (Dikow \& Grimaldi 2014). Here we report a single piece of Eocene amber with four pupae identified as those of a species of Asilidae. We discuss possible affinities and biological interpretations of this find.

\section{Material and Methods}

Material. - The study is based on a single piece of amber, with four inclusions. The amber piece (FMNH PE 61074) is part of the collection of the Field Museum of Natural History in Chicago (FMNH). The amber piece is most likely of Baltic origin.

Methods. - Specimens (inclusions) were documented on a Leica DM 2500P compound microscope (Leica, Wetzlar, Germany) with a ScopeTek DCM 510 ocular camera. For reducing the optical deformation induced by the oblique surfaces of the amber piece, a drop of glycerol was placed onto the region of interest and covered with a cover slip, leading to a plane surface. One inclusion is broken and hence exposed on the surface; in this case no glycerol was applied.

For lighting, external cold light sources with light fibres were used for distributing light evenly from a low angle. Fibre lights were equipped with polarisation filters; these were cross-polarised with a polariser within the microscope to reduce reflections.

Due to the limited depth of field, stacks were recorded (several frames of the same image detail in different focal planes). Focal planes were shifted manually. Resulting stacks were fused using the software program Image Analyzer (MeeSoft, Michael Vinther). Fused images have more structures in focus than any of the single frames. Virtual surfaces based on the unsharpness of the images were calculated for certain specimens. Although this method may produce certain artefacts due to the transparency of the amber, it provides additional topological information of the specimen (for methods see also Haug et al. 2013b, 2015b; Hörnig et al. 2016). 


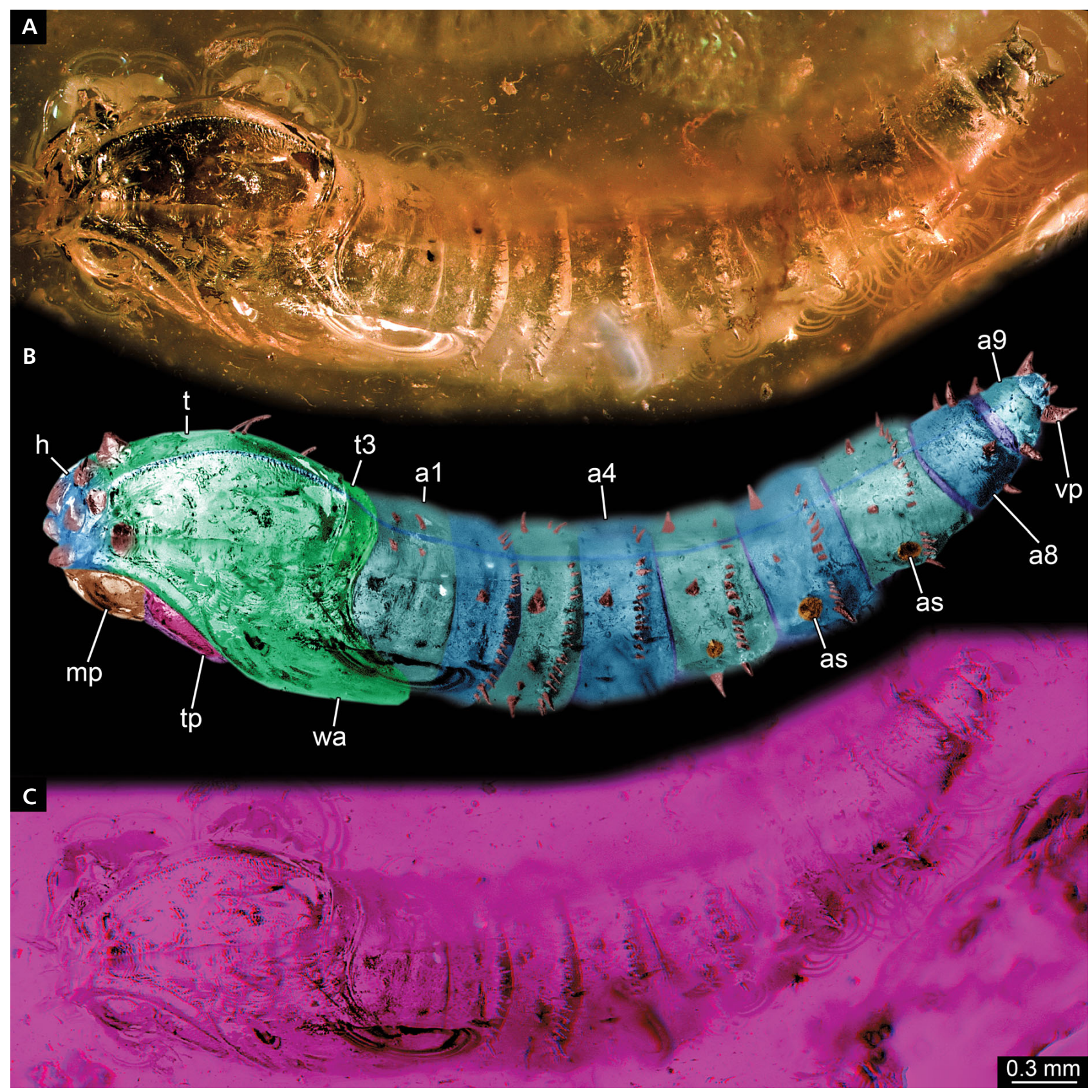

Figure 1. Specimen 1 of PE 61074 . A - overview image. $\bullet$ B - colour-marked version of A. $\bullet$ C - stereo image of specimen 1, please use red-cyan glasses to view. Abbreviations: $\mathrm{a} 1-\mathrm{a} 9=$ abdominal segments $1-9 ; \mathrm{as}=$ spine of abdominal segment; $\mathrm{h}=$ head capsule; $\mathrm{mp}=$ mouthparts; $\mathrm{t}=$ tergites of first and second thoracic segment (without visible subdivision); $\mathrm{t} 3=$ tergite of third thoracic segment; $\mathrm{t}$ = thoracopods; $\mathrm{vp}=$ ventral postero-lateral process; wa $=$ wing anlage.

\section{Results}

\section{Description of the amber piece}

The amber piece has four major inclusions further described below as specimens $1-4$. Furthermore, there are many additional small inclusions. These appear to be both plant remains and dirt particles.

\section{Specimen 1}

Preservation. - Amber surrounding specimen partly disturbed, most likely due to movements of specimen during embedding.

Orientation. - Largely lateral view on left body side, tilted slightly dorsally (Fig. 1). 
Total body length $5.0 \mathrm{~mm}$. Body organised into prominent anterior region (head and thorax) and posterior trunk (insect-type abdomen). Anterior region with weakly discriminated head region, anterior thorax region and distinct tergite of third thoracic segment (metanotum). Head region with vaguely visible blunt spine-like protrusions; further details not accessible due to disturbed amber surrounding this region.

Anterior thorax region without distinguishable subdivisions into tergites of first and second thoracic segment (pronotum, mesonotum). At anterior rim blunt spine (?) with three setae close to dorsal midline (on one body side, presumably same set on other side). Anterior two setae recognisable at about middle along anterior-posterior axis. Third seta at about three quarters along anterior-posterior axis. Dorsal outline of anterior thoracic region strongly convex. Dorsal midline of anterior thoracic region marked by slightly elevated crenulated crest. Antero-ventral outline of anterior thoracic region concave with slightly bulged rim. Postero-ventral outline of anterior thoracic region markedly drawn out postero-ventrally into lobate wing anlagen, partly covering succeeding segments. Tergite of third thoracic segment (metanotum) short, about $15 \%$ of length of anterior thoracic region. Lateral regions not observable, covered by wing anlagen.

Posterior trunk composed of nine or more segments. Abdominal segment 1 about 50\% of length of anterior thorax region with two spines on each side close to midline at about midlength along anterior-posterior axis. Abdominal segment 2 shorter than preceding segment with length of about $30 \%$ of anterior thoracic region, with one prominent spine located dorso-laterally at about half way along anterior-posterior axis. At posterior edge prominent row of slightly backward curved spines; at least 18 spines on one side of body. Abdominal segment 3 slightly longer than preceding segment, length about $35 \%$ of anterior thoracic region, with one prominent spine dorso-laterally at about two-fifths of distance along anterior-posterior axis. More ventrally along this line three slightly smaller prominent spines. Posterior edge with prominent row of slightly backward curved spines; at least 14 spines on one side of body. Abdominal segment 4 slightly longer than preceding segment, more than $40 \%$ of length of anterior thoracic region, with one prominent spine dorso-laterally at about two fifths along anterior-posterior axis. Posterior edge with prominent row of slightly backward curved spines; at least 11 spines on one side of body. Abdominal segment 5 about as long as preceding segment, but slightly smaller in diameter, with one prominent spine dorso-laterally at about two-fifths of distance along anterior-posterior axis. Further ventrally along this line possible spiracle, even further ventrally one further prominent spine. Posterior edge with prominent row of slightly backward curved spines; at least 11 spines on one side of body. Abdominal segment 6 slightly longer than preceding segment, but slightly smaller in diameter, with one prominent spine located dorso-laterally at about two-fifths of distance along anterior-posterior axis. Further ventrally along this line is a possible spiracle. Posterior edge with prominent row of slightly backward curved spines; at least 10 spines on one side of body. Abdominal segment 7 slightly longer than preceding segment, length about $45 \%$ of anterior thoracic region, but smaller in diameter, with one prominent spine dorso-laterally at about two-fifths of length along anterior-posterior axis. Further ventrally along this line is a possible spiracle. Posterior edge with prominent row of slightly backward curved spines; at least 11 spines on one side of body. Abdominal segment 8 shorter than preceding segment, length less than $30 \%$ of anterior thoracic region, but significantly smaller in diameter, with two prominent spines, one dorso-laterally, one further laterally, both relatively far posteriorly. Abdominal segment 9 shorter than preceding segment, length less than $25 \%$ of anterior thoracic region, significantly smaller in diameter, with two prominent spines (processes), one dorso-laterally, one further ventrally, both relatively far posteriorly. One additional spine on ventral side, larger in relation to preceding spines. Two additional smaller spines located far terminally.

Mouthparts postero-ventrally protruding from head. No details observable due to preservation. Thoracopods elongate and tube-like, on ventral side of thorax; no details available.

\section{Specimen 2}

Preservation. - Amber surrounding specimen partly disturbed, most likely due to movements of the specimen during embedding, but less than in specimen 1 (Fig. 2). Additionally, milky-appearing areas, possibly due to extrusion of gas.

Orientation. - Largely lateral view on left body side, tilted slightly ventrally.

Total body length $4.2 \mathrm{~mm}$. Body organised into prominent anterior region (head and thorax) and posterior trunk (insect-type abdomen). Anterior region with only part of thorax region distinguishable (due to orientation of specimen). Head region not accessible due to orientation of specimen.

Anterior thoracic region without distinguishable subdivisions into tergites of first and second thoracic segment (pronotum, mesonotum). Dorsal outline of anterior thoracic region not accessible. Dorsal midline of anterior thorax region not accessible due to orientation of specimen. Antero-ventral outline of anterior thoracic region concave. Postero-ventral outline of anterior thoracic region markedly drawn out postero-ventrally into a lobate wing anlage, partly covering succeeding segments. Tergite of third thoracic segment (metanotum) not accessible due to orientation of specimen. 


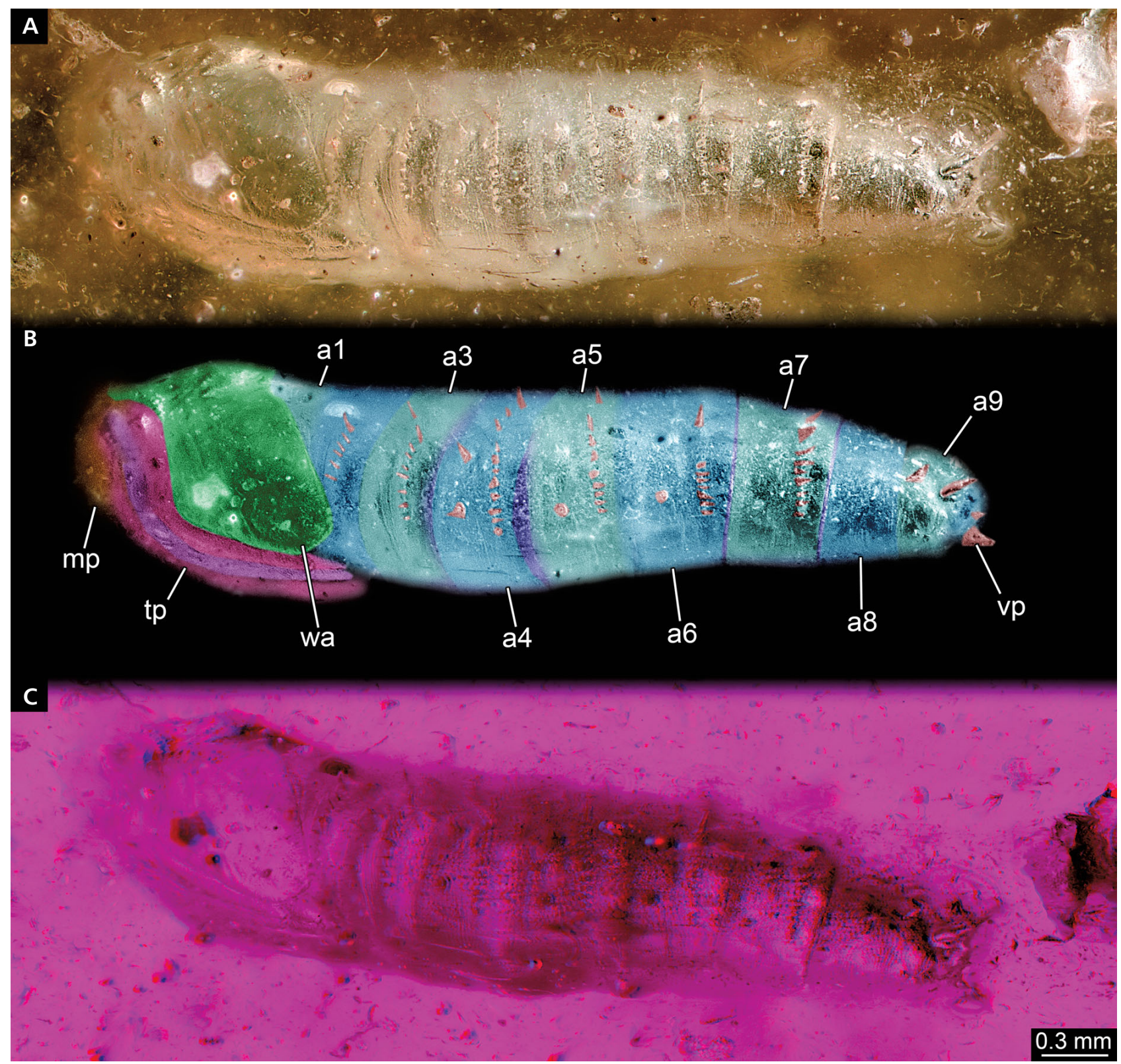

Figure 2. Specimen 2 of PE 61074. $\bullet$ A - overview image. $\bullet$ B - colour-marked version of A. $\bullet$ C - stereo image of specimen 2, please use red-cyan glasses to view. Abbreviations: $\mathrm{a} 1-\mathrm{a} 9=$ abdominal segments $1-9 ; \mathrm{h}=$ head capsule; $\mathrm{mp}=$ mouthparts; $\mathrm{t}=$ thoracopods; wa = wing anlage.

Posterior trunk composed of nine visible segments. Abdominal segment 1 about $50 \%$ of length of anterior thorax region. Abdominal segment 2 slightly shorter than preceding segment, exact length difficult to measure due to preservation. Posterior edge with prominent row of slightly backward curved spines; at least seven spines on one side of body. Abdominal segment 3 slightly longer than preceding segment, exact length difficult to measure due to preservation. Posterior edge with prominent row of slightly backward curved spines; at least 11 spines on one side of body. Abdominal segment 4 slightly longer than preceding segment, exact length difficult to measure due to preserva- tion. With one prominent spine laterally at about middle along anterior-posterior axis. Further ventrally along this line one further prominent spine. Posterior edge with prominent row of slightly backward curved spines; at least 11 spines on one side of body. Abdominal segment 5 about as long as preceding segment, but slightly smaller in diameter, with one prominent spine ventro-laterally at about middle along anterior-posterior axis. Posterior edge with prominent row of slightly backward curved spines; at least ten spines on one side of body. Abdominal segment 6 slightly longer than preceding segment, but slightly smaller in diameter, with one prominent spine ventro-laterally at 
about middle along anterior-posterior axis. Posterior edge with prominent row of slightly backward curved spines; at least 8 spines on one side of body. Abdominal segment 7 slightly longer than preceding segment, but smaller in diameter, with one prominent spine dorso-laterally at about two fifths along anterior-posterior axis. At posterior edge with prominent row of slightly backward curved spines; at least nine spines on one side of body. Abdominal segment 8 shorter than preceding segment and significantly smaller in diameter. Abdominal segment 9 shorter than preceding segment and significantly smaller in diameter, with a prominent spine (process) ventrally relatively far posteriorly. An additional smaller spine far terminally.

Mouthparts postero-ventrally protruding from head, poorly preserved. Thoracopods elongate and tube-like and situated on ventral side of thorax.

\section{Specimen 3}

Preservation. - Amber broken right through inclusion; inner side of inclusion largely exposed (Fig. 3). Amber surrounding specimen partly disturbed, most likely due to movements of specimen during embedding.

Orientation. - Largely lateral view on left body side.

Total (preserved) body length $4.4 \mathrm{~mm}$. Body organised into prominent anterior region (head and thorax) and posterior trunk (insect-type abdomen). Anterior region with discriminated head region, anterior thorax region and distinct tergite of third thoracic segment (metanotum). Head region with vaguely visible protrusions; further details not accessible due to broken nature of this region. Anterior thoracic region without distinguishable subdivisions into tergites of first and second thoracic segment (pronotum, mesonotum). Dorsal outline of anterior thorax region strongly convex. Dorsal midline of anterior thorax region not accessible due to orientation of specimen. Antero-ventral outline of anterior thoracic region concave. Posteroventral outline of anterior thoracic region markedly drawn out postero-ventrally into lobate wing anlage, partly covering succeeding segments.

Tergite of third thoracic segment (metanotum) short, about $15 \%$ of length of anterior thorax region. Lateral regions not observable, covered by wing anlagen.

Posterior trunk with at least six segments, posterior end not preserved. Abdominal segment 1 with about $50 \%$ of length of anterior thorax region, with two spines on one side close to midline at about middle along anterior-posterior axis. Abdominal segment 2 shorter than preceding segment, length about $30 \%$ of anterior thorax region, with one prominent spine dorso-laterally at about one third along anterior-posterior axis. Posterior edge with prominent row of slightly backward curved spines; at least three spines on one side of body. Abdominal segment 3 slightly longer than preceding segment, length of about $35 \%$ of anterior thoracic region, with one prominent spine dorso-laterally at about one third along anterior-posterior axis. Posterior edge with prominent row of slightly backward curved spines; at least three spines on one side of body. Abdominal segment 4 slightly longer than preceding segment, length of more than $40 \%$ of anterior thoracic region and with one prominent spine dorso-laterally at about one third along anterior-posterior axis. Further ventrally along this line one further prominent spine. Abdominal segment 5 about as long as preceding segment, with one prominent spine dorso-laterally about one third along anterior-posterior axis. Further ventrally along this line one further prominent spine. Abdominal segment 6 incompletely preserved, no details accessible. Abdominal segments 7-9 not preserved.

Mouthparts postero-ventrally protruding from head; poorly preserved. Thoracopods elongate and tube-like on ventral side of thorax.

\section{Specimen 4}

Preservation. - Amber surrounding specimen heavily disturbed, most likely due to movements of specimen during embedding (Fig. 4). Additionally milky-appearing areas, possibly due to extrusion of gas.

Orientation. - Largely dorsal view, tilted slightly onto left side.

Total body length $5.0 \mathrm{~mm}$. Body organised into prominent anterior region (head and thorax) and posterior trunk (insect-type abdomen). Anterior region with very weakly discriminated head region, anterior thorax region and vaguely distinguishable tergite of third thoracic segment (metanotum). Details of head region not accessible due to disturbed amber surrounding this region. Anterior thoracic region without distinguishable subdivisions into tergites of first and second thoracic segment (pronotum, mesonotum). Dorsal outline of anterior thoracic region not accessible. Dorsal midline of anterior thorax region marked by slightly elevated crenulated crest. Antero-ventral outline of anterior thorax region not accessible due to orientation of specimen. Postero-ventral outline of anterior thorax region difficult to access due to orientation of specimen. Tergite of third thoracic segment short, about $15 \%$ of length of anterior thorax region. Lateral regions not accessible due to disturbances in surrounding amber.

Posterior trunk composed of nine visible segments. Abdominal segment 1 about $50 \%$ of length of anterior thoracic region. Abdominal segment 2 slightly shorter than preceding segment; exact length difficult to measure due to preservation. Abdominal segment 3 slightly longer than preceding segment; exact length difficult to measure due to preservation. Abdominal segment 4 slightly longer than preceding segment; exact length difficult to measure due to 


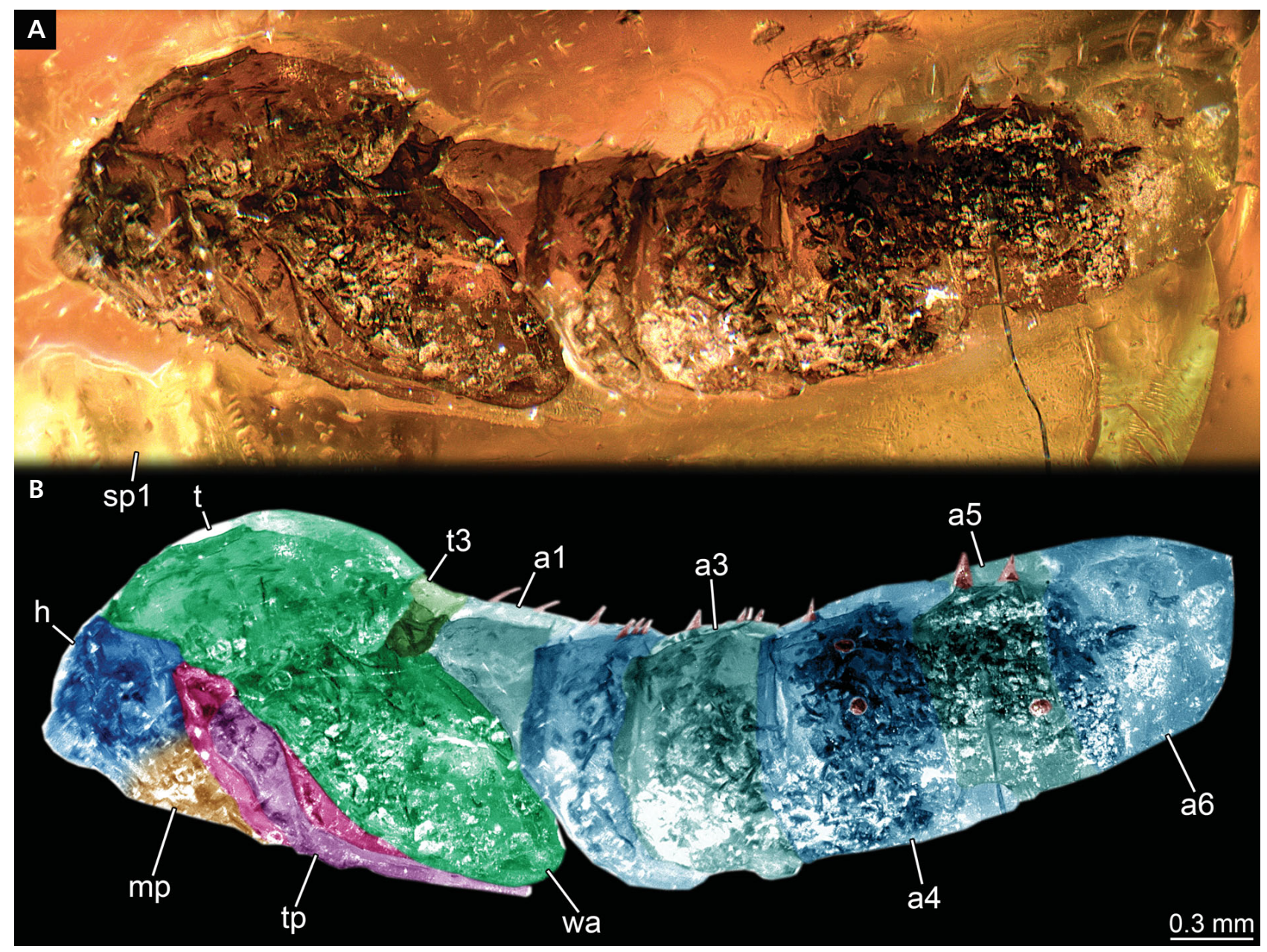

Figure 3. Specimen 3 of PE 61074. $\bullet$ A - overview-image. $\bullet B-$ colour-marked version of A. Abbreviations: a1-a6 = abdominal segments $1-6$; h = head capsule; $\mathrm{mp}=$ mouthparts; $\mathrm{t}=$ tergites of first and second thoracic segment (without visible subdivision); $\mathrm{sp} 1=$ posterior part of specimen $1 ; \mathrm{t} 3=$ tergite of third thoracic segment; $\mathrm{t}$ = thoracopods; wa = wing anlage.

preservation. Posterior edge with prominent row of slightly backward curved spines; at least three spines on one side of body. Abdominal segment 5 about as long as preceding segment. Posterior edge with prominent row of slightly backward curved spines; at least five spines on one side of body. Abdominal segment 6 slightly longer than preceding segment; exact length difficult to measure due to preservation. Posterior edge with prominent row of slightly backward curved spines; at least four spines on one side of body. Abdominal segment 7 slightly longer than preceding segment, but smaller in diameter at posterior edge, with a prominent row of slightly backward curved spines; at least two spines on one side of body. Abdominal segment 8 shorter than preceding segment, significantly smaller in diameter, with prominent spine, one dorso-laterally accompanied by smaller spine. Abdominal segment 9 shorter than preceding segment, significantly smaller in diameter, with prominent spine (process) dorso-laterally relatively far posteriorly. Additionally, smaller spine far terminally.
Mouthparts not accessible due to orientation of specimen. Thoracopods not accessible due to orientation of specimen.

\section{Discussion}

\section{Systematic interpretation}

Based on the overall similarities among the four specimens we interpret them as conspecific; differences in observed features being most likely preservational. This accounts also for the body lengths as the specimens are preserved slightly bent and/or tilted in the amber, which complicates exact measurements. Also the perspective in which the specimens are accessible influences the visible length and may lead to underestimations.

Based on the overall morphology of the specimens they represent pupa stages (see schematic drawing in Fig. 5). As 
the pupa is an autapomorphic character of Holometabola, the four specimens are immature holometabolans. The presence of a single pair of wing anlagen in all specimens indicates a position within Diptera.

A pupa with pronounced rows of spines on the abdominal segments is characteristic for Asilidae (Dennis et al. 2013). This is also compatible with the presence of stouter spines on the head (although not very well preserved in the fossil specimens). We tried to identify a more precise systematic position within Asilidae with the key of Dennis \& Knutson (1988). These authors distinguished five major sub-groups ("subfamilies"): Leptogastrinae, Asilinae, Dasypogoninae, Megapodinae, and Laphriinae. Leptogastrinae is characterised by a pupa with hair-like structures instead of true spines on the abdominal segments and hence differs from the specimens described herein. Furthermore, Leptogastrinae is characterised by a pupa with a single pair of processes (spines) on the terminal abdominal segments, while in the described specimens there are at least two pairs.

The other asilid sub-groups have pupae with true spines on the abdominal segments and more than a single pair of processes on the terminal segment. Asilinae and Dasypogoninae are both characterised by a pupa with a longer dorsal process on the terminal segment. Laphriinae is characterised by a ventral process of the pupa, which is longer than the dorsal one seen in the described specimens. Megapodinae seems to be largely characterised by specifics of the head structures. As such structures are not easily observed in our specimens, we cannot find positive (nor negative) characters that would argue for (or against) a position of the described specimens in Megapodinae. While it is suboptimal that these characters cannot be taken into account, the morphology of the ventral process of the specimens gives a positive signal that the fossils are pupae of a representative of Laphriinae.

It is in general difficult to infer the relationship of a fossil based on keys for modern faunas, nor do keys offer a proper phylogenetic treatment. But it seems unlikely that a phylogenetic analysis of Asilidae incorporating pupal characters will be produced soon, which would be necessary to fully evaluate the fossils described here. We therefore see the use of modern keys as a reasonable (but sub-optimal) compromise.

Discussing the possible positions of the fossils within Laphriinae is challenging. One could argue that, as the fossils have been found in Europe, a key for European laphriine assassin flies should provide the best result. There are two shortcomings for such an approach: 1) The standard key for European species is provided by Melin (1923). Despite this work representing a kind of standard we were unable to access it. 2) Possibly more importantly, in the Eocene numerous insect groups were present in Germany that are now considered to be endemic in South
America, South Africa or Australia (see e.g. discussion in Wedmann et al. 2011 and references therein). Hence, the use of a key for species now present in Europe will not necessarily provide a better result than a key for other regions. For this reason and due to better availability we used the key provided by Dennis \& Barnes (2013). The authors differentiate three major species groups ("genera"): Lampria, Laphria and Andrenosoma. According to the key, representatives of Lampria possess a pupa with a broad spine medio-dorsally on abdominal segment 1, which is bifurcate or trifurcate. This area is well preserved in specimen 1 , but does not show such a spine. Hence, the specimens are probably not representatives of Lampria. Most other characters necessary for a further determination cannot be accessed in the fossil specimens. Hence, the specimens may be representatives of Laphria or Andrenosoma. We also cannot exclude the possibility that they are representatives of a now extinct lineage within Laphriinae, or even only closely related to Laphriinae.

\section{Rarity of the find}

As pointed out above, pupa stages of holometabolous insects are rare in the fossil record. Although dipteran fossils are very common (especially in amber), fossil findings of adult representatives of Asilidae are extremely uncommon (recently reviewed in Dikow \& Grimaldi 2014). With this, our find of an assassin fly pupa is very exceptional.

The oldest possible (but partly controversial) fossil asilids known so far are from late Jurassic (Evenhuis 1994) and early Cretaceous (Grimaldi 1990). Among them are two species from the Crato Formation in Brazil (Grimaldi 1990, Grimaldi \& Engel 2005) and two Burmese amber fossils (Dikow \& Grimaldi 2014).

Further amber inclusions of asilid flies came from New Jersey amber (Grimaldi \& Cumming 1999), Dominican amber and Malagasy copal (Scarbrough \& Poinar 1992, Dikow \& Bayless 2009). Baltic amber has also yielded asilids (Schumann 1984, Geller-Grimm 1998, Gröhn 2015), including a single pupa (Gröhn 2015). The amber piece described herein is hence only the second report of a pupa of an asilid fly in the fossil record, possibly the first one of a species of Laphriinae, and is unique due to the fact that there are four specimens in one piece of amber. This latter aspect demands for further discussion.

\section{Biological interpretation: Lifestyle of assassin fly larvae}

The life style, specific developmental requirements and the morphology of assassin fly larvae is only known for two percent of the species of Asilidae, and even there only incom- 


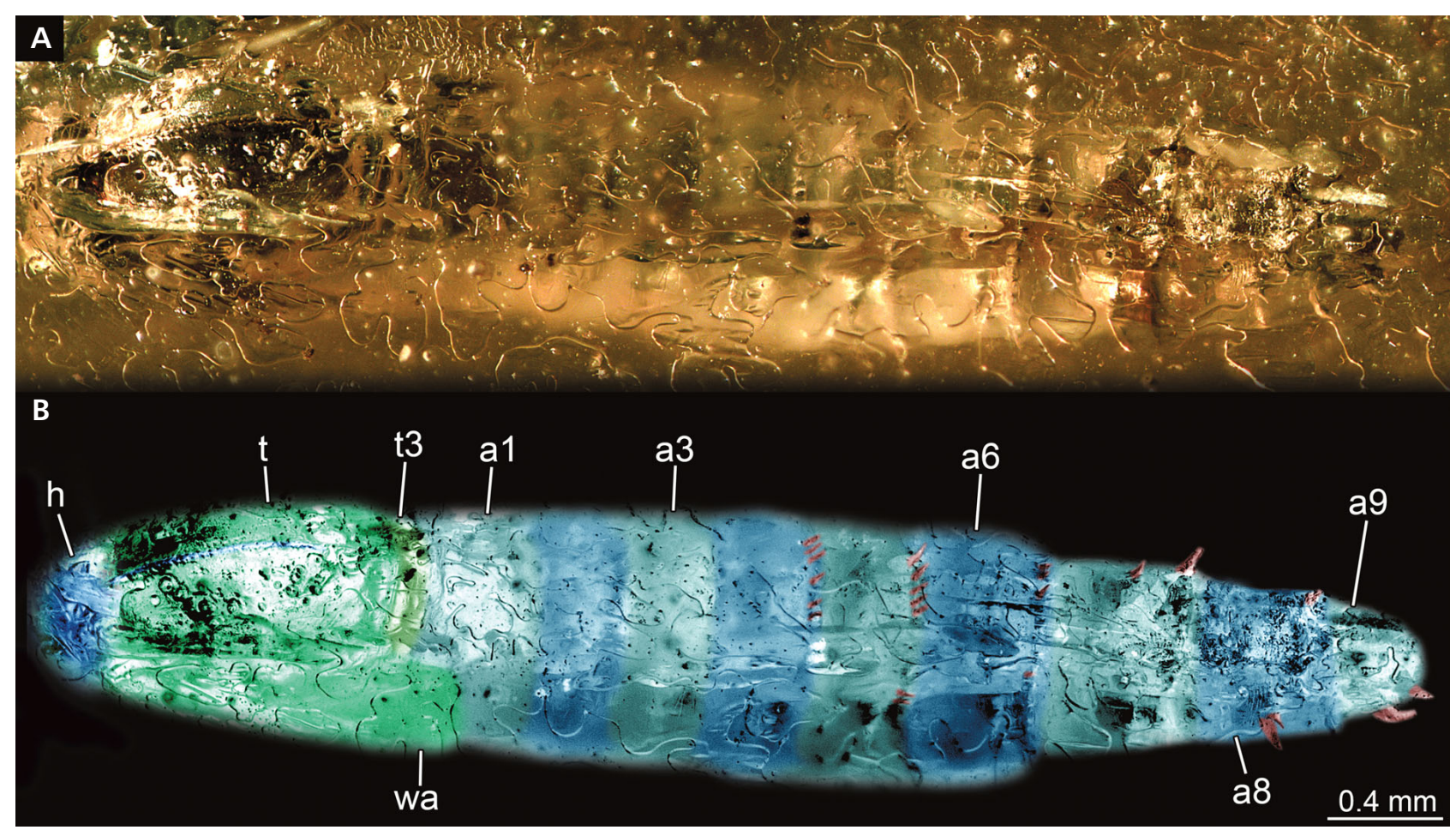

Figure 4. Specimen 4 of PE 61074 . A - overview-image. $\bullet B-$ colour-marked version of A. Abbreviations: a1-a9 = abdominal segments 1-9; $\mathrm{h}=$ head capsule; $\mathrm{t}=$ tergites of first and second thoracic segment (without visible subdivision); $\mathrm{t} 3=$ tergite of third thoracic segment; wa $=$ wing anlage.

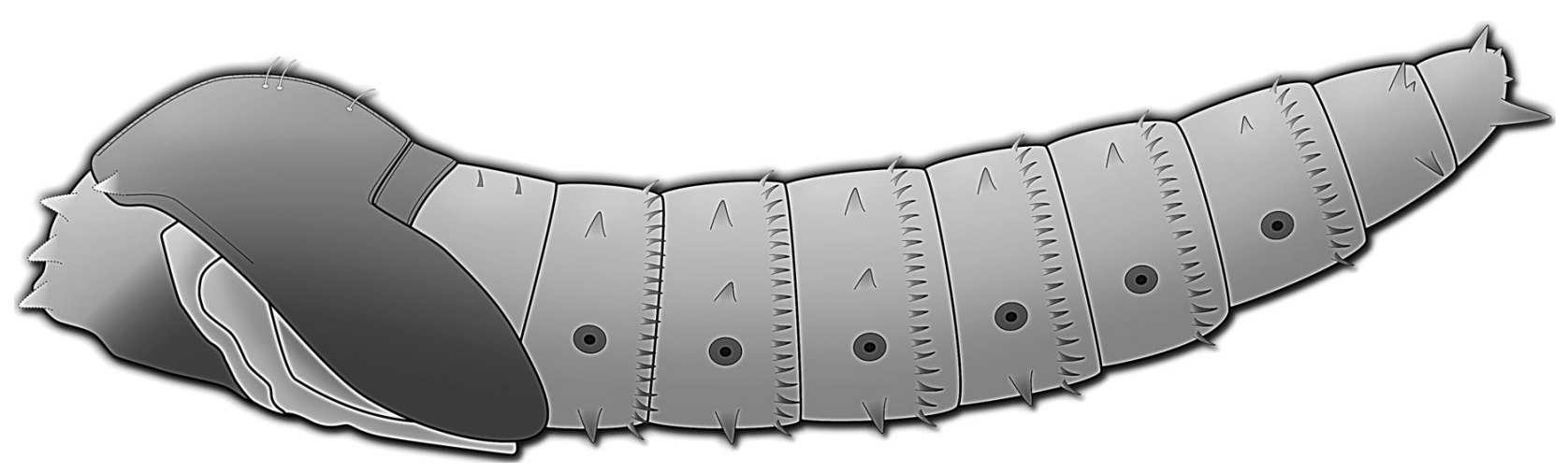

Figure 5. Schematic drawing based on pupal specimens of PE 61074.

pletely (Castelo et al. 2006, Dennis et al. 2008, Dikow 2009). What is known seems consistent throughout the group:

\section{In general}

Many assassin fly larvae are predatory or ectoparasitic (in the broad sense, see below) on immature stages of other insects in the soil or within dead wood (Knutson 1972, Dennis \& Knutson 1988, Stubbs \& Drake 2001). For example, the larvae of Promachus yesonicus are free-living predators of larval scarabaeid beetles. Larvae of Mallophora ruficauda also feed on larval scarabaeid beetles, but live attached to the host during their development (Castelo \&
Capurro 2000, Castelo et al. 2006). The larvae have been reported to finally kill their hosts, when they are ready to pupate, thus assassin fly larvae are parasites in the broad sense, but more specifically should be considered as ectoparasitoids (Musso 1983). Important for understanding the fossils herein is the fact that if more than one parasitoid is attached to a single host (superparasitism), only one survives to reach the adult stage (Castelo et al. 2006, Castelo \& Crespo 2012). After the larvae have pupated and completed development, the mobile pupa will move to the surface, and emerge after up to 20 days as adults, leaving behind their pupal case sticking vertically out of the soil (for soil-dwelling forms; Cannings 1997). 


\section{More specifically}

Larvae of Laphriinae occur in rotten wood, especially in pines, but also in hollow fruit trees, aspen and spruce (Dufour 1850; Bromley 1934; Oldroyd 1972; Cannings 1989, 1997; Dennis \& Barnes 2012). Not surprisingly, females of Laphriinae (but also Laphystiinae) are known for depositing eggs in groups into dead wood using their comparably long and cylindrical ovipositors (White 1916, Weiss \& West 1922, Bromley 1934, Cannings 1997, Dikow 2009, Dennis \& Barnes 2014).

Larvae of Laphriinae are also predators and ectoparasitoids, due to their habitat, especially on xylophagous insects (Lehr 1977, Geller-Grimm 2002). The larvae live in the galleries of wood-boring insects, such as those of weevils (Curculionidae) or wood wasps (Siricidae), and some produce their own galleries (Oldroyd 1972, Cannings 1997, Dennis \& Barnes 2013). Overall, the larvae have been described as fairly active (Greene 1917). The non-free-living forms have been reported to be ectoparasitoids on the larvae of jewel beetles (Buprestidae) and longhorn beetles (Cerambycidae) that nest in tree stumps (Brauer 1883, Cerezke 1973, Fischer 1983, Dennis \& Knutson 1988, Barriga 1990). Also in species of Laphriinae the pupae move to the surface (here of the dead wood) and the adults emerge (Bromley 1934, Musso 1967, Dennis \& Barnes 2012, Dennis \& Barnes 2014).

\section{Biological interpretation: Do larvae of Laphriinae aggregate?}

The amber piece with four pupae described herein has no indication of possible host/prey. A case of four assassin fly pupae occurring together is rather surprising, given the rareness of pupae and asilids in general, but also based on the life style of assassin fly pupae. Hence, the condition that leads to this co-occurrence is not immediately apparent. Based on observations of extant assassin fly larvae, it seems unlikely that the group was the result of active aggregation or gregarious behaviour of larvae unless the site offered ideal conditions for pupation.

Castelo \& Capurro (2000) reported that female asilids choose their oviposition site based on the aggregation of possible host species. These authors concentrated on Asilinae and not on Laphriinae, but the information may still be relevant.

In the case of Laphriinae, the hosts are mainly larvae of xylophagous insects. One such group, longhorn beetles, have females that lay on average 120 eggs in a single tree stump (Donley 1978). On average, 600 longhorn beetle larvae have been reported alive per tree (Fierke et al. 2005). Longhorn beetles show a very carefully timed life cycle (Fierke et al. 2005). Coupled to this, this can be also assumed for asilids, further corroborated by a very limited and specific flight period of many species within Laphriinae (Cannings 1997) and the triggered emergence of the pupae by temperature and light (Baker \& Fischer 1975). Ritcher (1940) reported up to 40 predatory assassin fly larvae engaging a single beetle pupa. This means comparably high densities of assassin fly larvae and pupae in certain localities but within short time frames.

Based on the observation on extant relatives, we assume that the fossil pupae also developed from larvae feeding on larvae of xylophagous insects in dead wood, either as predators or as ectoparasitoids. We further speculate that several pupae emerged to the surface of the wood more or less at the same moment and rather close together. Presumably, the here described group was enclosed in this short time frame, by a drop of resin from a living tree.

Hence, this case of co-occurrence likely does not reflect active aggregation behaviour of the enclosed animals but more likely is the result of an association of individuals in a particular timeframe. The find represents an extremely unusual case and displays a poorly documented episode in the development of extinct assassin flies.

\section{Acknowledgements}

This study benefitted from the support of various persons and institutions. We would like to thank Paul Mayer, Chicago, for the access and help in the collections. The manuscript heavily benefitted from comments by Torsten Dikow, Washington, D.C., and and an anonymous reviewer. The language of the manuscript was kindly improved by Nigel Hughes, Riverside. JTH was kindly funded by the Alexander von Humboldt Foundation and by Yale University with a Feodor Lynen Fellowship, and supported by Derek E.G. Briggs. MKH and CN are currently funded by Ph.D. fellowships of the Studienstiftung des deutschen Volkes. MKH would also like to thank Steffen Harzsch, Greifswald, for his support. JTH, CN and CH thank J. Matthias Starck for his support and inspiring discussions. We furthermore want to thank all people indirectly supporting our work by open source, open access or low cost software, such as OpenOffice, Image Analyzer, and CombineZM/ZP.

\section{References}

Andersen, T., Baranov, V., Goral, T., Langton, P., Perkovsky, E. \& SYKES, D. 2015. First record of a Chironomidae pupa in amber. Geobios 48(4), 281-286.

DOI 10.1016/j.geobios.2015.06.004

BAKER, N.T. \& FisheR, R.L. 1975. A taxonomic study of the Asilidae of Michigan. The Great Lakes Entomologist 8, 28-92.

BARRIGA, T.J.E. 1990. Parasites and larval predators of Cerambycidae and Buprestidae (Coleoptera) of Chile. Revista Chilena de Entomología 18, 57-60. 
Brandão, C.R.F., Urbani, C.B., Wagensberg, J. \& Yamamoto, C.I. 1998. New Technomyrmex in Dominican amber (Hymenoptera: Formicidae), with a reappraisal of Dolichoderinae phylogeny. Insect Systematics \& Evolution 29(4), 411-428. DOI 10.1163/187631298X00041

BraUER, F. 1883. Die Zweiflügler des Kaiserlichen Museums zu Wien. III. Systematische Studien auf Grundlage der Dipteren-Larven nebst einer Zusammenstellung von Beispielen aus der Literatur über dieselben und Beschreibung neuer Formen. Denkschriften der Kaiserlichen Akademie der Wissenschaften. Mathematisch-Naturwissenschaftliche Classe 47, 1-100.

Brodeur, J. \& Boivin, G. 2004. Functional ecology of immature parasitoids. Annual Review of Entomology 49, 27-49. DOI 10.1146/annurev.ento.49.061703.153618

BRomLey, S.W. 1934, The laphriine robber flies of North America (Diptera: Asilidae). 359 pp. Ph.D. thesis, The Ohio State University, Columbus, USA.

CAnNings, R.A. 1989. The robber flies (Diptera: Asilidae) of a Festuca Grassland in the Okanagan Valley, British Columbia. Journal of the Entomological Society of British Columbia 86, 14-26.

Cannings, R.A. 1997. Robber flies (Diptera: Asilidae) of the Yukon, 637-662. In Danks, H.V. \& Downes, J.A. (eds) Insects of the Yukon. Biological Survey of Canada (Terrestrial Arthropods), Ottawa.

Castelo, M.K. \& Capurro, A.F. 2000. Especificidad y densodependencia inversa en parasitoides con oviposicíon fuera del hospedador: el caso de Mallophora ruficauda (Diptera: Asilidae) en la pampa Argentina. Ecología Austral 10, 89-101.

CAstelo, M.K. \& Corley, J.C. 2004. Oviposition behavior in the robber fly Mallophora ruficauda (Diptera: Asilidae). Annals of the Entomological Society of America 97, 1050-1054. DOI 10.1603/0013-8746(2004)097[1050:OBITRF]2.0.CO;2

CAstelo, M.K. \& CRESPo, J.E. 2012. Incidence of non-immunological defences of soil white grubs on parasitism success of Mallophora ruficauda larva (Diptera: Asilidae). Insects 3(3), 692-708. DOI 10.3390/insects3030692

CAstelo, M.K. \& LAZZARI, C.R. 2004. Host-seeking behavior in larvae of the robber fly Mallophora ruficauda (Diptera: Asilidae). Journal of Insect Physiology 50(4), 331-336. DOI 10.1016/j.jinsphys.2004.02.002

Castelo, M.K., Ney-Nifle, M., Corley, J.C. \& Bernstein, C. 2006. Oviposition height increases parasitism success by the robber fly Mallophora ruficauda (Diptera: Asilidae). Behavioral Ecology and Sociobiology 61(2), 231-243. DOI 10.1007/s00265-006-0254-5

CEREZKE, H.F. 1973. Some parasites and predators of Hylobius warreni in Alberta. Bi-monthly Research Notes 29, 24-25.

Crespo, J.E. \& CASTElo, M.K. 2009. Insights to host discrimination and host acceptance behaviour in a parasitoid (Diptera: Asilidae): Implications for fitness. Journal of Insect Physiology 55, 1072-1078. DOI 10.1016/j.jinsphys.2009.08.002

DAvis, S.R., EngEL, M.S. \& ReN, D. 2010. A pupal caddisfly from the Early Cretaceous of China (Trichoptera). Cretaceous Research 31(4), 396-399. DOI 10.1016/j.cretres.2010.05.001
Dennis, D.S. 2012. Ethology of Proctacanthus brevipennis (Wiedemann, 1828) (Diptera: Asilidae) in Northeastern Florida, USA. Journal of the Entomological Research Society 14, 91-109.

DenNIS, D.S. 2013. Ethology of Stichopogon trifasciatus (Say, 1823) (Diptera: Asilidae) in Northeastern Florida, USA. Journal of the Entomological Research Society 15, 37-50.

Dennis, D.S. \& BARnes, J.K. 2012. The pupal case of a Palearctic robber fly, Andrenosoma atrum (Linnaeus) (Diptera: Asilidae). Proceedings of the Entomological Society of Washington 114, 16-22. DOI 10.4289/0013-8797.114.1.16

Dennis, D.S. \& Barnes, J.K. 2013. Pupal cases of four Nearctic species of Laphria (Diptera: Asilidae). Zootaxa 3681(4), 478-492. DOI 10.11646/zootaxa.3681.4.9

Dennis, D.S. \& BARnES, J.K. 2014. The pupal case of Nearctic and Neotropical robber fly Andrenosoma cruentum (McAtee, 1919) (Diptera: Asilidae). Journal of the Entomological Research Society 16, 51-60.

Dennis, D.S. \& KNutson, L. 1988. Descriptions of pupae of South American robber flies (Diptera: Asilidae). Annals of the Entomological Society of America 81, 851-864.

DOI 10.1093/aesa/81.6.851

Dennis, D.S. \& Lavigne, R.J. 1979. Ethology of Machimus callidus with incidental observations on $M$. occidentalis in Wyoming (Diptera: Asilidae). Pan-Pacific Entomologist 55, 208-221.

Dennis, D.S., Barnes, J.K. \& Knutson, L. 2013. Review and analysis of information on the biology and morphology of immature stages of robber flies (Diptera: Asilidae). Zootaxa 3673, 1-64. DOI 10.11646/zootaxa.3673.1.1

Dennis, D.S., Barnes, J.K. \& KnUtson, L. 2008. Pupal cases of Nearctic robber flies (Diptera: Asilidae). Zootaxa 1868, 1-98.

Dennis, D.S., Lavigne, R.J. \& Bullington, S.W. 1986. Ethology of Efferia cressoni with a review of the comparative ethology of the genus (Diptera: Asilidae). Proceedings of the Entomological Society of Washington 88, 42-55.

Diкоw, T. 2009. A phylogenetic hypothesis for Asilidae based on a total evidence analysis of morphological and DNA sequence data (Insecta: Diptera: Brachycera: Asiloidea). Organisms Diversity \& Evolution 9(3), 165-188. DOI 10.1016/j.ode.2009.02.004

Dikow, T. \& BAYLESS, K.M. 2009. Taxonomic revision of the genus Schildia Aldrich, 1923 (Diptera: Asilidae: Leptogastrinae) with the description of new extant and extinct species. Insect Systematics \& Evolution 40(3), 253-289. DOI 10.1163/187631209X458358

Dikow, T. \& Grimaldi, D.A. 2014. Robber flies in Cretaceous ambers (Insecta: Diptera: Asilidae). American Museum Novitates 3799, 1-19. DOI 10.1206/3799.1

Donley, D.E. 1978. Oviposition by the red oak borer, Enaphalodes rufulus (Coleoptera: Cerambycidae). Annals of the Entomological Society of America 71, 496-498. DOI 10.1093/aesa/71.4.496

Dufour, L. 1850. Recherches pour server a l'historie des métamorphoses des Asiliques. Annales des Science Naturalles, Series 3, Zoology 13, 141-158. 
Evenhuis, N.L. 1994. Catalogue of the fossil flies of the world (Insecta: Diptera). 608 pp. Backhuys Publishers, Leiden.

Fierke, M.K., Kinney, D.L., SAlisbury, V.B., Crook, D.J. \& StePHEN, F.M. 2005. Development and comparison of intensive and extensive sampling methods and preliminary within-tree population estimates of red oak borer (Coleoptera: Cerambycidae) in the Ozark Mountains of Arkansas. Environmental Entomology 34, 184-192.

DOI 10.1603/0046-225X-34.1.184

Fischer, E.M. 1983. Pilica formidolosa (Mosca Asesina, Robber Fly), 755-758. In JANZEN, D.H. (ed.) Costa Rican Natural History. University of Chicago Press, Chicago.

FISCHER, T.C. 2015. Pupal exuvia of an adelid case-bearing moth (Lepidoptera) from Bitterfeld amber (Eocene). Zitteliana 55, 41-43.

Geller-Grimm, F. 1998. Protoloewinella keilbachi Schumann, 1984 from the Baltic amber (Diptera: Asilidae). Studia Dipterologica 5(1), 84 .

Geller-Grimm, F. 2002. Robber flies (Diptera: Asilidae) of the Socotra Archipelago, Yemen. Fauna of Arabia 19, 467-489.

Godfray, H.C.J. 1994. Parasitoids: behavior and evolutionary ecology. 488 pp. Princeton University Press, Princeton.

GreENE, C. T. 1917. A contribution to the biology of North American Diptera. Proceedings of the Entomological Society of Washington 1, 146-161.

GrIMALDI, D.A. 1990. Insects from the Santana Formation, Lower Cretaceous, of Brazil. Bulletin of the American Museum of Natural History 195, 1-191.

Grimaldi, D.A., \& Cumming, J.M. 1999. Brachyceran Diptera in Cretaceous ambers and Mesozoic diversification of the Eremoneura. Bulletin of the American Museum of Natural History 239, 1-124.

GRIMALDI, D.A. \& Engel, M.S. 2005. Evolution of the insects. 755 pp. Cambridge University Press, New York.

GRÖHN, C. 2015. Einschlüsse im Baltischen Bernstein. 424 pp. Wachholtz, Kiel.

Haug, J.T., Audo, D., Charbonnier, S. \& Haug, C. 2013a. Diversity of developmental patterns in achelate lobsters-today and in the Mesozoic. Development Genes \& Evolution 223, 363-373. DOI 10.1007/s00427-013-0452-x

Haug, J.T., Hädicke, C.W., Haug, C. \& Hörnig, M.K. 2015b. A possible hatchling of a jumping bristletail in 50 million years old amber. Neues Jahrbuch für Geologie und Paläontologie, Abhandlungen 278, 191-199. DOI 10.1127/njgpa/2015/0523

Haug, J.T., Haug, C. \& Garwood, R. 2016. Evolution of insect wings and development - new details from Palaeozoic nymphs. Biological Reviews 91, 53-69.

DOI 10.1111/brv.12159

Haug, J.T., Martin, J.W. \& Haug, C. 2015a. A 150-million-year-old crab larva and its implications for the early rise of brachyuran crabs. Nature Communications 6, art. 6417. DOI 10.1038/ncomms7417

Haug, J.T., Müller, C.H.G. \& Sombke, A. 2013b. A centipede nymph in Baltic amber and a new approach to document amber fossils. Organisms Diversity \& Evolution 13, 425-432. DOI 10.1007/s13127-013-0129-3

Hayat, R. 1997. Prey of some robber flies (Diptera: Asilidae) in Turkey. Zoology in the Middle East 15, 87-94.

DOI 10.1080/09397140.1997.10637743

Hörnig, M.K., Sombke, A., Haug, C., Harzsch, S. \& Haug, J.T. 2016. What nymphal morphology can tell us about parental investment - a group of cockroach hatchlings in Baltic Amber documented by a multi-method approach. Palaeontologia Electronica 19(1), art. 5A.

Hugueney, M., TAchet, H., \& Escuillié, F. 1990. Caddisfly pupae from the Miocene indusial limestone of SaintGérand-le-Puy, France. Palaeontology 33(2), 495-502.

HuLL, F.M. 1962. Robber flies of the world. Bulletin of the United States National Museum 224(1-2), 1-907.

DOI 10.5479/si.03629236.224

JoERn, A. \& RudD, N.T. 1982. Impact of predation by the robber fly Proctacanthus milbertii (Diptera: Asilidae) on grasshopper (Orthoptera: Acrididae) populations. Oecologia 52, 42-46. DOI 10.1007/BF00386716

Johnston, J.E. \& Borkent, A. 1998. Chaoborus lichtenstein (Diptera: Chaoboridae) pupae from the middle Eocene of Mississippi. Journal of Paleontology 72(3), 491-493. DOI 10.1017/S0022336000024252

KNUTSON, L. 1972. Pupa of Neomochtherus angustipennis (Hine), with notes on feeding habits of robber flies and a review of publications on morphology of immature stages (Diptera: Asilidae). Proceedings of the Biological Society of Washington 85, 163-178.

Lavigne, R.J. \& Dennis, D.S. 1975. Ethology of Efferia frewingi (Diptera: Asilidae). Annals of the Entomological Society of America 68, 992-996. DOI 10.1093/aesa/68.6.992

Lavigne, R.J. \& Dennis, D.S. 1980. Ethology of Proctacanthella leucopogon in Mexico (Diptera: Asilidae). Proceedings of the Entomological Society of Washington 82, 260-268.

Lavigne, R.J., Dennis, D.S. \& Gowen, J.A. 1978. Asilid literature update 1956-1976. University of Wyoming Agriculture Experiment Station Science Monograph 36, 1-134.

LeHR, P.A. 1977. Robber flies from the subfamilies Atomosiinae and Laphriinae (Diptera, Asilidae) from Central Asia and Kazakhstan. Entomological Review 56, 123-131.

LuKASHEvich, E. 2012. Pupae of Mesozoic Oryctochlus Kalugina, 1985 (Chironomidae: Podonominae), with description of two new species. Fauna Norvegica 31, 1-159. DOI 10.5324/fn.v31i0.1400

Lukashevich, E. \& PrzhiBoro, A.A. 2015. A new tribe of Diamesinae (Diptera: Chironomidae) from the Lower Cretaceous of Mongolia. Cretaceous Research 52, 562-569. DOI 10.1016/j.cretres.2014.03.016

Melin, D.E. 1923. Contributions to the knowledge of the biology, metamorphosis and distribution of the Swedish asilids in relation to the whole family of asilids. Zoologiska Bidrag Från Uppsala 8, 1-137.

Minelli, A., Brena, C., Deflorian, G., Maruzzo, D. \& Fusco, G. 2006. From embryo to adult-beyond the conventional periodization of arthropod development. Development Genes 
\& Evolution 216(7-8), 373-383.

DOI 10.1007/s00427-006-0075-6

Musso, J.J. 1967 Étude de la nymphe d'Andrenosoma bayardi Séguy, 1952 (Dipt. Asilidae). Bulletin de la Société entomologique de France 72, 75-80.

Musso, J.J. 1978 Recherches sur le développement, la nutrition et l'ecologia des Asilidae (Diptera-Brachycera). 312 pp. Ph.D. thesis, Universite de Droit d'Economie et des Sciences d'Aix-Marseille, Marseille, France.

Musso, J.J. 1981. Morphology and development of the immature stages of some robber flies (Diptera: Brachycera: Asilidae). Entomologia Generalis 7, 89-104.

Musso, J.J. 1983. Nutritive and ecological requirements of robber flies (Diptera: Brachycera: Asilidae). Entomologia Generalis 9, 35-50. DOI 10.1127/entom.gen/9/1983/35

Oldroyd, H. 1972. Two robber flies (Diptera: Asilidae) of unusual structure. Journal of Natural History 6, 635-642. DOI 10.1080/00222937200770571

Pape, T., Blagoderov, V. \& Mostovski, M.B. 2011. Order Diptera Linnaeus 1785. Zootaxa 3148, 222-229.

Perkovsky, E.E. 2008. First occurrence of syninclusion of ants Lasius schiefferdeckeri Mayr (Hymenoptera, Formicidae) and aphids Germaraphis ungulata Heie (Homoptera, Aphidinea) in amber (Klesov). Russian Entomological Journal 17(2), 207-208.

PoInAR, G. 2004. Evidence of parasitism by Strepsiptera in Dominican amber. Biocontrol 49(3), 239-244. DOI 10.1023/B:BICO.0000025393.15395.b6

Pritchard, A.E. 1935. New Asilidae from the Southwestern United States (Diptera). American Museum Novitates 813, $1-14$.

Ritcher, P.O. 1940. Kentucky white grubs. Kentucky Agricultural Experiment Station Bulletin 401, 71-157.

Rudolf, N.R., HAUG, C. \& Haug, J.T. 2016. Functional morphology of giant mole crab larvae: a possible case of defensive enrollment. Zoological Letters 2, art. 17.

Scarbrough, A.G., \& Poinar, JR., G.O. 1992. Upper Eocene rob- ber flies of the genus Ommatius (Diptera: Asilidae) in Dominican amber. Insecta Mundi 6(1), 13-18.

SchumanN, H. 1984. Erstnachweis einer Raubfliege aus dem Sächsischen Bernstein (Diptera: Asilidae). Deutsche Entomologische Zeitschrift 31, 217-223.

Shurovnekov, B.G. 1962. Field entomophagous predators (Coleoptera, Carabidae, and Diptera, Asilidae) and factors determining their efficiency. Entomological Review 41, 476-485.

Stubbs, A.E. \& DraKe, M. 2001. British soldierflies and their allies. An illustrated guide to their identification and ecology, covering all flies (Diptera) in the families Acroceridae, Asilidae, Athericidae, Bombyliidae, Rhagionidae, Scenopinidae, Stratiomyidae, Tabanidae, Therevidae, Xylomyidae and Xylophagidae. 528 pp. British Entomological and Natural History Society, Reading.

Veltz, I., Azar, D. \& Nel, A. 2007. New chironomid flies in Early Cretaceous Lebanese amber (Diptera: Chironomidae). African Invertebrates 48(1), 169-191.

Wedmann, S., Hoernschemeyer, T. \& Schmied, H. 2011. Fossil water-penny beetles (Coleoptera: Psephenidae: Eubrianacinae) from the Eocene of Europe, with remarks on their phylogenetic position and biogeography. Palaeontology 54, 965-980. DOI 10.1111/j.1475-4983.2011.01088.x

Weiss, H.B. \& West, E. 1922. The insects and plants of a moist woods on the Piedmont Plain of New Jersey. Journal of the New York Entomological Society 30(4), 169-191.

Weitschat, W. \& Wichard, W. 1998. Atlas der Pflanzen und Tiere im Baltischen Bernstein. 256 pp. Dr. Friedrich Pfeil Verlag, München.

White, A. 1916. The Diptera-Brachycera of Tasmania: Part III. Families Asilidae, Bombylidae, Empidae, Dolichopodidae and Phoridae. Papers \& Proceedings of the Royal Society of Tasmania 1916, 148-266. DOI 10.5962/bhl.part.28993

WolfF, M. \& Lamas, C.J.E. 2016. Family Asilidae. Zootaxa 4122(1), 353-371. DOI 10.11646/zootaxa.4122.1.17

Wood, G.C. 1981. Asilidae. Manual of Nearctic Diptera 1, 549-573. 